\title{
New Nanomagnetic Heterogeneous Cobalt Catalyst for the Synthesis of Aryl Nitriles and Biaryls
}

\author{
Hadis Hosseini Moghadam, Sara Sobhani,* and José Miguel Sansano
}

Cite This: ACS Omega 2020, 5, 18619-18627

Read Online

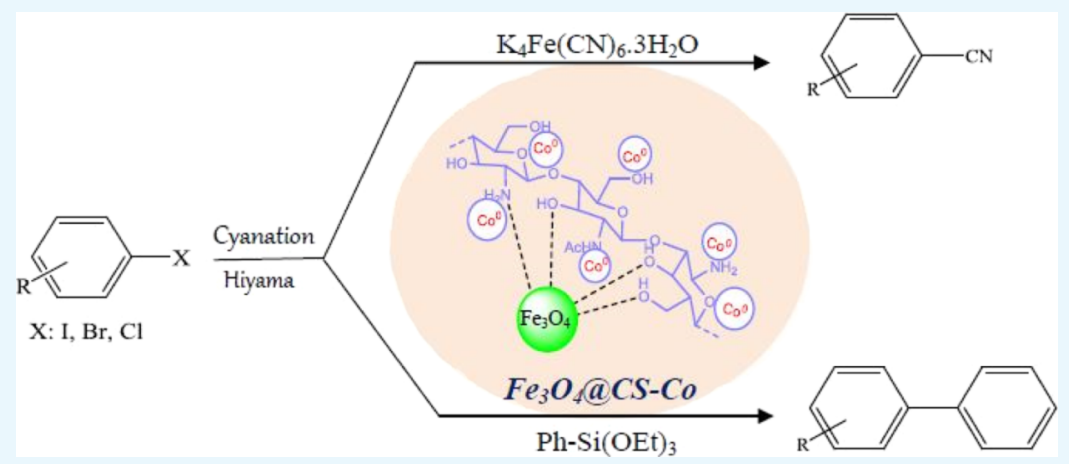

ABSTRACT: Cobalt nanoparticles immobilized on magnetic chitosan $\left(\mathrm{Fe}_{3} \mathrm{O}_{4} @ \mathrm{CS}-\mathrm{Co}\right)$ have been prepared. They were identified using various techniques such as Fourier-transform infrared spectroscopy, X-ray diffraction, field emission scanning electron microscopy, energy-dispersive X-ray spectroscopy, transmission electron microscopy, thermogravimetric analysis, vibrating sample magnetometry, X-ray photoelectron spectroscopy, and inductively coupled plasma atomic emission spectroscopy analysis and applied efficiently as a cobalt catalyst in the cyanation and fluoride-/palladium-free Hiyama reactions of different types of aryl halides employing $\mathrm{K}_{4}\left[\mathrm{Fe}(\mathrm{CN})_{6}\right] \cdot 3 \mathrm{H}_{2} \mathrm{O}$ and triethoxyphenylsilane, respectively. After each reaction, the catalyst was isolated and reused for the second run. The catalytic activity of the catalyst was not lost apparently even after five runs. No considerable changes in its chemical structure and morphology were observed. It is worth to note that in this paper, the cobalt catalyst has been used for the first time for the cyanation of aryl halides.

\section{INTRODUCTION}

Aryl nitriles are significant structural units of different biologically active compounds, agrochemicals, dyes, and natural products. ${ }^{1}$ Nitriles are important building blocks in the synthesis of heterocycles as they are transformed into a range of functional groups such as amines, carboxylic acids, oximes, amidines, and ketones. ${ }^{2}$ The Rosenmund-von Braun reaction, ammoxidation of toluene, and diazotization of anilines, followed by the Sandmeyer reaction are known as the conventional methods for the synthesis of aryl nitriles. ${ }^{3}$ The reaction of aryl halides with cyanating agents in the presence of transition metals as catalysts are the most powerful protocols for the synthesis of aryl nitriles. ${ }^{4}$ Along this line, cyanation reactions have been reported in the presence of transition metals, such as $\mathrm{Pd},{ }^{5} \mathrm{Ni}^{6}{ }^{6} \mathrm{Rh},{ }^{7} \mathrm{Ir}^{8}$ and $\mathrm{Cu},{ }^{9}$ using different cyanide reagents such as copper, potassium, sodium, and zinc cyanide, trimethylsilyl cyanide, phenyl cyanates, acetone cyanohydrins, and benzyl thiocyanates. ${ }^{10}$ In recent years, potassium hexacyanoferrate(II) trihydrate $\left\{\mathrm{K}_{4}[\mathrm{Fe}\right.$ $\left.\left.(\mathrm{CN})_{6}\right] \cdot 3 \mathrm{H}_{2} \mathrm{O}\right\}$, which is a nonhygroscopic, commercially accessible, easily handled, and inexpensive cyanide source, has been applied for the cyanation of aryl halides. ${ }^{11}$ In most cases, a stable cyanide complex with transition metals is formed, and it deactivates the transition-metal catalysts. However, slow in situ generation of cyanide ions from $\mathrm{K}_{4}\left[\mathrm{Fe}(\mathrm{CN})_{6}\right] \cdot 3 \mathrm{H}_{2} \mathrm{O}$ improves the efficiency of the metal catalyst. ${ }^{12}$

Biaryl structures are found in numerous physiologically active compounds including natural products, pharmaceuticals, agrochemicals, organic materials, and organocatalysts. ${ }^{13}$ Performing reactions of aryl halides with organometallic reagents in the presence of $\mathrm{Pd}$ as a catalyst is the most attractive method for the preparation of biaryl compounds. Organoboron (Suzuki-Miyaura), organomagnesium (Kuma$\mathrm{da}-$ Corriu), organozinc (Negishi), and organotin (Stille) derivatives are the most general organometallic reagents that are used for this purpose. ${ }^{14}$ However, these organometallic compounds have intrinsic drawbacks for practical uses,

Received: March 5, 2020

Accepted: June 24, 2020

Published: July 22, 2020 
Scheme 1. Schematic Illustration for the Synthesis of $\mathrm{Fe}_{3} \mathrm{O}_{4} @ \mathrm{CS}-\mathrm{Co}$
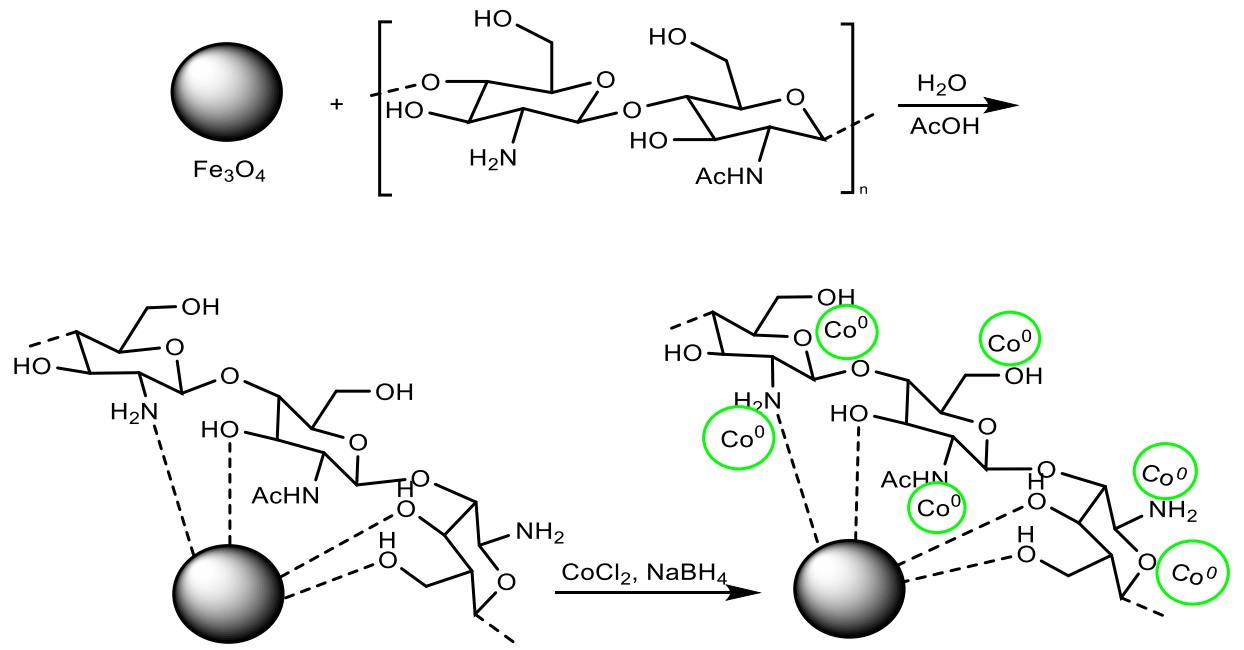

including high toxicity, low stability, sensitivity to humidity or water, and poor biocompatibility. In recent years, low toxic, broadly available, low-cost, environmentally benign, and highly stable silicon compounds have received a lot of attention as fascinating reagents for the Hiyama reaction. ${ }^{15}$

In particular, the mostly used transition-metal catalysts for the Hiyama cross-coupling and cyanation reactions are $\mathrm{Pd}$ catalysts. However, some drawbacks of palladium-based catalysts such as high cost, sensitivity to air, and formation of ineffective palladium cyanide species in the cyanation reactions encouraged the search for the $\mathrm{C}-\mathrm{C}$ coupling reactions without using palladium catalysts. ${ }^{16}$ In this regard, cobalt-based catalytic systems, as a viable alternative to palladium, have gained much interest in organic chemistry because of their low cost and availability. ${ }^{17}$ Along this line, a number of methods using cobalt catalysts for improving of Suzuki-Miyaura, Sonogashira, and Heck-Mizoroki crosscoupling reactions have been reported. ${ }^{18}$

During the past decades, magnetic nanoparticles (MNPs), which have been extensively studied for different biological and medical applications, have attracted much attention as smart materials for supporting catalysts because of their ease of preparation and functionalization, high surface area, and low cost and toxicity. ${ }^{19}$ The most important feature of MNPs is their simple magnetic separation using an external magnet, which is an economic isolation method for industrial applications. Magnetic separation is more valuable than timeconsuming filtration, centrifugation, or other workup techniques, as it avoids loss of the nanosized catalysts and increases the product's purity. However, the catalytic activity of MNPs is decreased by the agglomeration during the catalytic reaction. Therefore, modification of MNPs by a variety of materials such as precious metals, ${ }^{20}$ silica, $^{21}$ carbon, $^{22}$ and biopolymers ${ }^{23}$ could prevent them from aggregation. Chitosan as a biopolymer has valuable properties such as hydrophilicity, biocompatibility, and biodegradability. ${ }^{24}$ It has several amino and hydroxyl groups, which can be used for further modification with specific components, such as nanoparticles, drugs, and other functional groups. ${ }^{25}$ For these reasons, magnetic chitosan has been widely synthesized and applied in catalytic reactions. ${ }^{26}$

In the past few years, we have been making effort in developing heterogeneous nanocatalysts for organic reac- tions. ${ }^{27}$ Recently, we have introduced a heterogeneous cobalt catalytic system (mTEG-CS-Co-Schiff-base) for Hiyama, Mizoroki-Heck, Suzuki, and Hirao cross-coupling processes. ${ }^{28}$ We have found that this catalyst was unsuccessful for the cyanation reaction of aryl halides. To improve our ongoing work, in this paper, we introduced cobalt nanoparticles immobilized on magnetic chitosan $\left(\mathrm{Fe}_{3} \mathrm{O}_{4} @ \mathrm{CS}-\mathrm{Co}\right)$ as a new catalyst. This catalyst was identified using a variety of methods such as Fourier-transform infrared (FT-IR) spectroscopy, energy-dispersive X-ray spectroscopy (EDX), field emission scanning electron microscopy (FE-SEM), transmission electron microscopy (TEM), X-ray diffraction (XRD), vibrating sample magnetometry (VSM), thermogravimetric analysis (TGA), X-ray photoelectron spectroscopy (XPS), and inductively coupled plasma atomic emission spectroscopy (ICP-AES) analysis and used as a nanomagnetic heterogeneous cobalt catalyst in the cyanation and Hiyama crosscoupling reactions. It is worth to note that here, we report for the first time, the employment of a cobalt catalyst in the cyanation reaction of aryl halides.

\section{RESULTS AND DISCUSSION}

2.1. Synthesis of $\mathrm{Fe}_{3} \mathrm{O}_{4} @ C S-C o$. $\mathrm{Fe}_{3} \mathrm{O}_{4} @ C S-\mathrm{Co}$ was synthesized as outlined in Scheme 1. The $\mathrm{Fe}_{3} \mathrm{O}_{4}$ nanoparticles, which were obtained by chemical coprecipitation protocol, were coated by chitosan to obtain $\mathrm{Fe}_{3} \mathrm{O}_{4} @ \mathrm{CS}$. Cobalt nanoparticles were immobilized on $\mathrm{Fe}_{3} \mathrm{O}_{4} @ \mathrm{CS}$ by adsorption of $\mathrm{CoCl}_{2}$ on $\mathrm{Fe}_{3} \mathrm{O}_{4} @ \mathrm{CS}$, followed by reduction with $\mathrm{NaBH}_{4}$. The catalyst was characterized by FT-IR spectroscopy, XRD, FE-SEM, EDX, TEM, TGA, VSM, XPS, and ICP-AES.

The FT-IR spectra of $\mathrm{Fe}_{3} \mathrm{O}_{4}, \mathrm{CS}, \mathrm{Fe}_{3} \mathrm{O}_{4} @ \mathrm{CS}$, and $\mathrm{Fe}_{3} \mathrm{O}_{4} @$ CS-Co are shown in Figure 1. In the FT-IR spectrum of $\mathrm{Fe}_{3} \mathrm{O}_{4}$ NPs, a strong stretching absorbance peak at $573 \mathrm{~cm}^{-1}$ that refers to $\mathrm{Fe}-\mathrm{O}$ groups is observed (Figure 1a). In the spectrum of chitosan (Figure 1b), a broad peak at 3700-3000 $\mathrm{cm}^{-1}$ can be ascribed to the stretching vibrations of $\mathrm{O}-\mathrm{H}$ and $\mathrm{N}-\mathrm{H}$ bonds. The other characteristic peaks appeared at 1661, $1378,1154,1073$, and $1033 \mathrm{~cm}^{-1}$ that corresponded to $\mathrm{N}-\mathrm{H}$ (bending), $\mathrm{C}-\mathrm{H}$ (bending aliphatic), $\mathrm{C}-\mathrm{O}-\mathrm{C}$ bridge, $\mathrm{C}-\mathrm{O}$ (stretching), and $\mathrm{C}-\mathrm{N}$ (stretching), respectively. In the FT-IR spectrum of $\mathrm{Fe}_{3} \mathrm{O}_{4} @ \mathrm{CS}$, all characteristic peaks of $\mathrm{Fe}_{3} \mathrm{O}_{4} \mathrm{NPs}$ and chitosan exist (Figure 1c). These observations indicate that successful coating of $\mathrm{Fe}_{3} \mathrm{O}_{4}$ with chitosan was achieved. In 


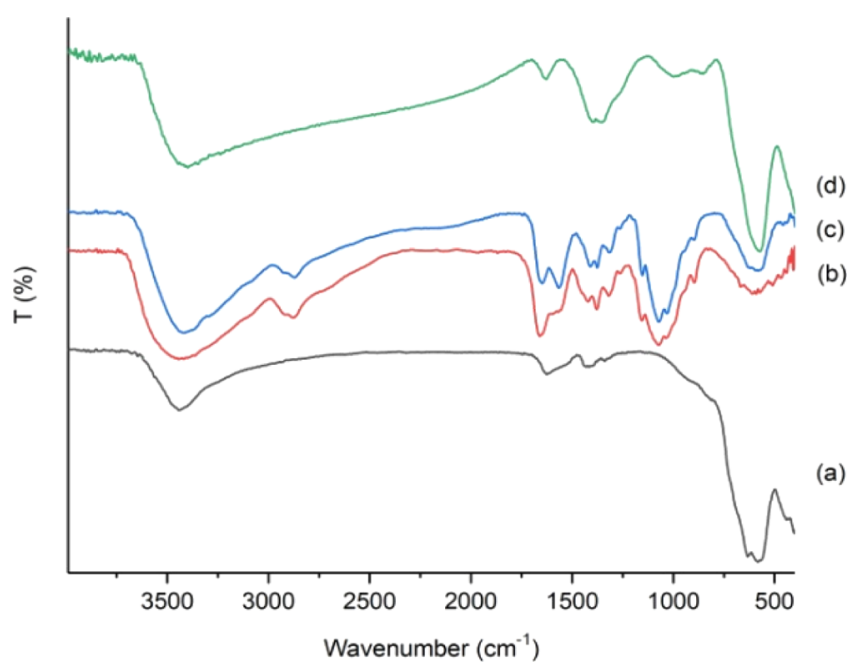

Figure 1. FT-IR spectra of (a) $\mathrm{Fe}_{3} \mathrm{O}_{4}$, (b) CS, (c) $\mathrm{Fe}_{3} \mathrm{O}_{4} @ \mathrm{CS}$, and (d) $\mathrm{Fe}_{3} \mathrm{O}_{4} @$ CS-Co.

the case of $\mathrm{Fe}_{3} \mathrm{O}_{4} @ \mathrm{CS}-\mathrm{Co}$, the entrapment of cobalt in the chitosan matrix led to changes in the $1000-1700 \mathrm{~cm}^{-1}$ region of the spectrum (Figure 1d). Slight shifting and changes in the intensity of these bands may account for the interaction of cobalt species with the $\mathrm{O}$ and $\mathrm{N}$ atoms in chitosan.

The XRD pattern of chitosan and $\mathrm{Fe}_{3} \mathrm{O}_{4} @ C S-C o$ are depicted in Figure 2. A broad peak at $21^{\circ}$ in the XRD pattern of CS corresponds to the amorphous characteristic of CS (Figure 2a). In the XRD pattern of $\mathrm{Fe}_{3} \mathrm{O}_{4} @ \mathrm{CS}$-Co (Figure $2 \mathrm{~b})$, strong diffraction peaks at 30.7, 35.75, 43.6, 53.9, 57.5,

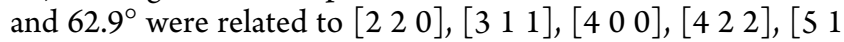
1], and $\left[\begin{array}{lll}4 & 4 & 0\end{array}\right]$ planes of the cubic $\mathrm{Fe}_{3} \mathrm{O}_{4}$ lattice. Diffraction peaks of amorphous CS and Co-NPs appeared at 21 and $75.5^{\circ}$,
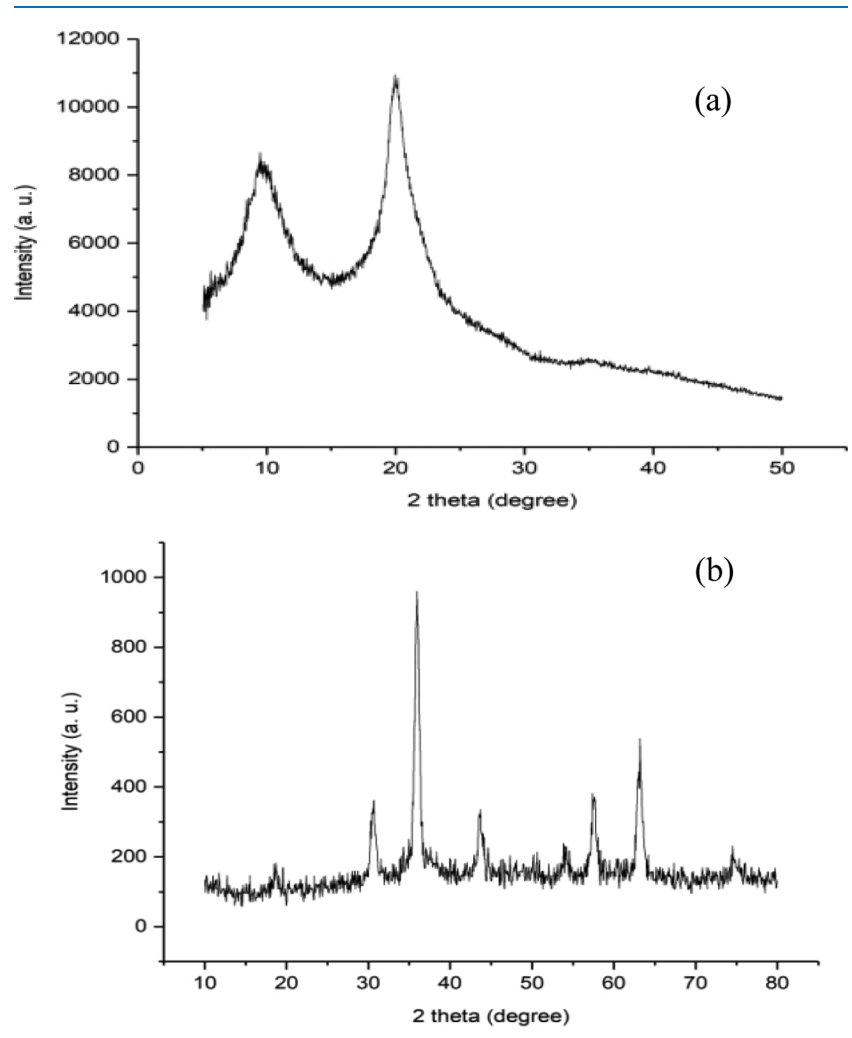

Figure 2. XRD patterns of (a) CS and (b) $\mathrm{Fe}_{3} \mathrm{O} @ \mathrm{CS}-\mathrm{Co}$. respectively. The strength of the diffraction peaks of CS decreased in $\mathrm{Fe}_{3} \mathrm{O}_{4} @ \mathrm{CS}$-Co because of the attachment of $\mathrm{Fe}_{3} \mathrm{O}_{4}$ to $\mathrm{CS}$ through the amino and hydroxyl groups.

The nanofeature, morphology, and shape of $\mathrm{Fe}_{3} \mathrm{O} @ \mathrm{CS}-\mathrm{Co}$ were investigated using its TEM and FE-SEM images. The TEM and FE-SEM images (Figure 3a,b) showed that the NPs were spherical in shape. The mean diameter size of the NPs is $18 \mathrm{~nm}$ (Figure 3d). On comparison of the TEM image of $\mathrm{Fe}_{3} \mathrm{O}_{4} @$ CS-Co (Figure 3a) with that of $\mathrm{Fe}_{3} \mathrm{O}_{4}$ (Figure 3c), it was found that $\mathrm{Fe}_{3} \mathrm{O}_{4} @ \mathrm{CS}-\mathrm{Co}$ dispersed considerably. The EDX analysis ensured the existence of $\mathrm{Fe}, \mathrm{Co}, \mathrm{C}, \mathrm{N}$, and $\mathrm{O}$ elements in $\mathrm{Fe}_{3} \mathrm{O}_{4} @ \mathrm{CS}-\mathrm{Co}$ (Figure 4). Elemental mapping of $\mathrm{Co}, \mathrm{N}, \mathrm{Fe}, \mathrm{C}$, and $\mathrm{O}$ in the $\mathrm{Fe}_{3} \mathrm{O}_{4} @ \mathrm{CS}-\mathrm{Co}$ nanocatalyst (Figure 5) indicated the consistent distribution of these elements on the catalyst surface. According to the ICP-AES analysis, the cobalt content of $\mathrm{Fe}_{3} \mathrm{O}_{4} @ \mathrm{CS}$-Co was calculated to be $22.87 \mathrm{wt} \%$.

The TG curve of $\mathrm{Fe}_{3} \mathrm{O}_{4} @ \mathrm{CS}$-Co showed a weight loss around 40\%, which corresponded to the elimination of absorbed water and thermal decomposition of the chitosan (Figure 6).

Magnetic properties of different steps of the catalyst preparation were characterized by VSM. The magnetic curves are shown in Figure 7. These curves showed that the approximate saturation magnetization value of $\mathrm{Fe}_{3} \mathrm{O}_{4} @ C S$ is $50 \mathrm{emu} \mathrm{g}^{-1}$. The reduction in the saturation magnetization of this compound compared to that in the pure MNPs ( $80 \mathrm{emu}$ $\left.\mathrm{g}^{-1}\right)$ is due to the coating of $\mathrm{Fe}_{3} \mathrm{O}_{4}$ by polymeric layers of CS. An increase in the saturation magnetization of $\mathrm{Fe}_{3} \mathrm{O}_{4} @ \mathrm{CS}-\mathrm{Co}$ was observed, which is a good evidence of successful immobilization of cobalt on $\mathrm{Fe}_{3} \mathrm{O}_{4} @$ CS.

$\mathrm{Fe}_{3} \mathrm{O}_{4} @ \mathrm{CS}$-Co was also characterized by XPS spectroscopy (Figure 8). Figure 8a confirms the existence of $\mathrm{Co}, \mathrm{Fe}, \mathrm{O}$, and $\mathrm{C}$ elements in the catalyst. In the $\mathrm{C} 1 \mathrm{~s}$ spectrum (Figure $8 \mathrm{~b}$ ), signals of binding energies located at $284.6(\mathrm{C}-\mathrm{C}$ and $\mathrm{C}-\mathrm{H})$, $286.03(\mathrm{C}-\mathrm{OH}$ and $\mathrm{C}-\mathrm{N})$, and $288.2(\mathrm{~N}-\mathrm{C}=\mathrm{O}) \mathrm{eV}$ were observed. ${ }^{29}$ Figure $8 \mathrm{c}$ reveals typical cobalt $(0)$ absorptions at 780.3 and $796.07 \mathrm{eV}$ for $2 \mathrm{p}_{3 / 2}$ and $2 \mathrm{p}_{1 / 2}$, respectively. ${ }^{30}$ The peaks at $782.3\left(2 \mathrm{p}_{3 / 2}\right)$ and $798.09 \mathrm{eV}\left(2 \mathrm{p}_{1 / 2}\right)$ indicated that a little amount of cobalt is in the oxidation state of $\mathrm{II}^{30}$ The weak satellite peaks were observed at around 785.8, 788.6, 801.3 , and $803.0 \mathrm{eV}$. These satellite peaks indicated the existence of $\mathrm{Co}_{3} \mathrm{O}_{4}$ on the surface of the catalyst. ${ }^{31}$

2.2. Cyanation of Aryl Halides Using $\mathrm{K}_{4}\left[\mathrm{Fe}(\mathrm{CN})_{6}\right] \cdot$ $3 \mathrm{H}_{2} \mathrm{O}$ Catalyzed by $\mathrm{Fe}_{3} \mathrm{O}_{4} @ \mathrm{CS}-\mathrm{Co}$. After the structural characterization of $\mathrm{Fe}_{3} \mathrm{O}_{4} @ C S-\mathrm{Co}$, its reactivity as a nanomagnetic heterogeneous cobalt catalyst was investigated in the cyanation reaction of aryl halides. To find the best reaction conditions, some reactions were performed in the presence of $\mathrm{Fe}_{3} \mathrm{O}_{4} @ C S-\mathrm{Co}$, using iodobenzene with variation in cyanide sources, temperature, base, solvent, and the amount of the catalyst (Table 1). Based on the results indicated in Table 1 , $\mathrm{K}_{4}\left[\mathrm{Fe}(\mathrm{CN})_{6}\right] \cdot 3 \mathrm{H}_{2} \mathrm{O}$, dimethylformamide (DMF), $\mathrm{Et}_{3} \mathrm{~N}, 100$ ${ }^{\circ} \mathrm{C}$, and $5 \mathrm{~mol} \%$ of the catalyst were chosen as the best conditions. A similar reaction was also investigated using $\mathrm{CoCl}_{2}$, and it was found that the desired final product was generated in poor yield after $24 \mathrm{~h}$ (Table 1, entry 14).

To further investigate the scope and limitations of this protocol, various types of aryl halides were selected and allowed to react using the optimized reaction parameters (Table 2). Different aryl chlorides, bromides, and iodides underwent the cyanation reaction and produced the desired aryl nitriles from good to high yields. 

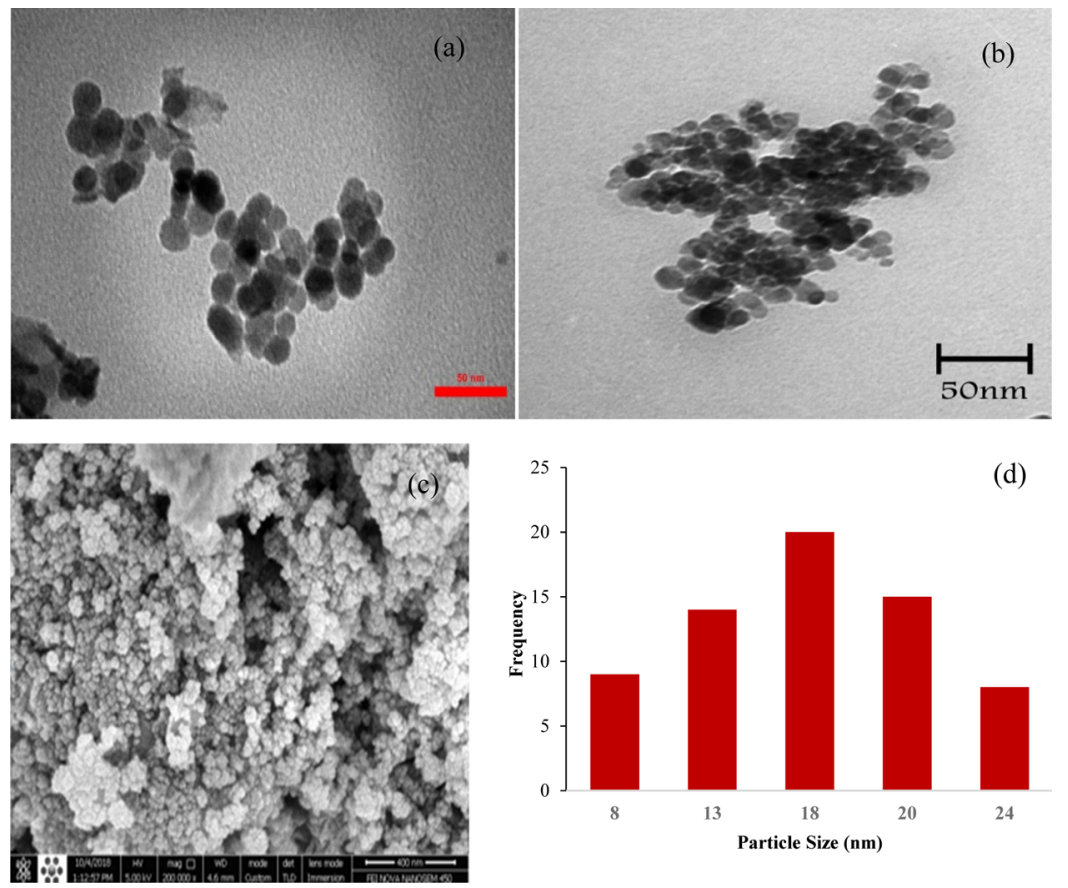

Figure 3. TEM images of (a) $\mathrm{Fe}_{3} \mathrm{O}_{4} @$ CS-Co and (b) $\mathrm{Fe}_{3} \mathrm{O}_{4}$, (c) FE-SEM image of theFe $\mathrm{O}_{4} @$ @C-Co nanocatalyst, and (d) size distribution of $\mathrm{Fe}_{3} \mathrm{O}_{4} @ \mathrm{CS}-\mathrm{Co}$.

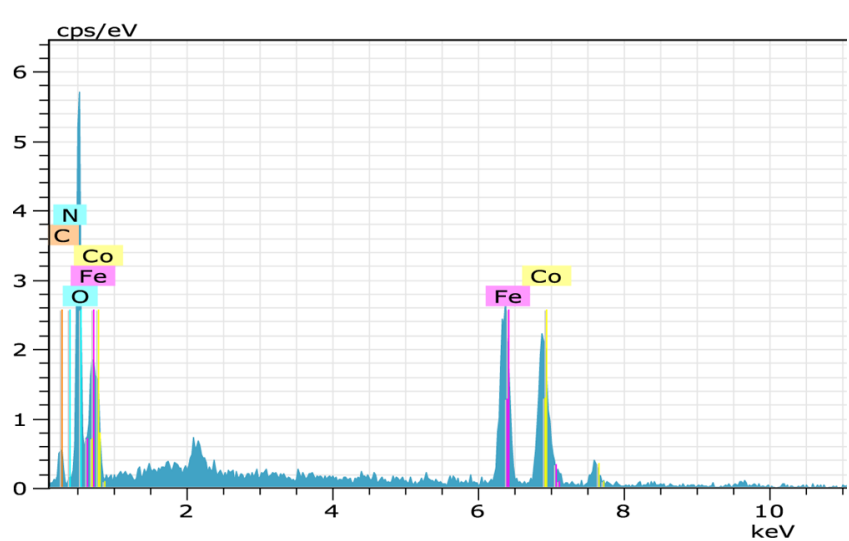

Figure 4. EDX analysis of $\mathrm{Fe}_{3} \mathrm{O}_{4} @ \mathrm{CS}-\mathrm{Co}$.

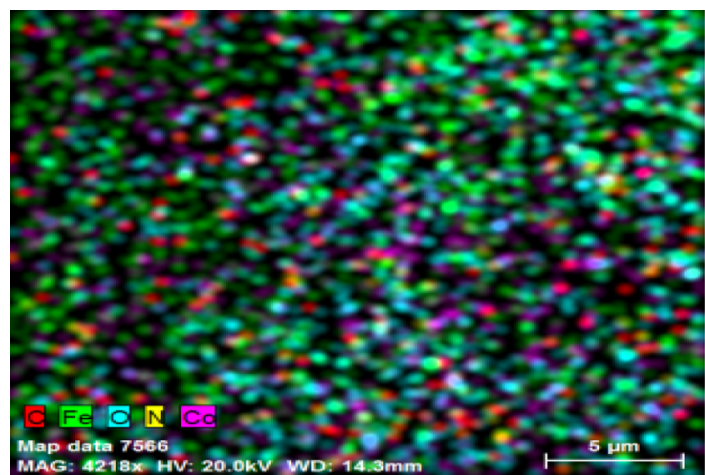

Figure 5. Elemental mapping of $\mathrm{Fe}_{3} \mathrm{O}_{4} @ \mathrm{CS}-\mathrm{Co}$.

With regard to the recyclability of $\mathrm{Fe}_{3} \mathrm{O}_{4} @ \mathrm{CS}-\mathrm{Co}$ in the cyanation reaction of iodobenzene using $\mathrm{K}_{4}\left[\mathrm{Fe}(\mathrm{CN})_{6}\right] \cdot 3 \mathrm{H}_{2} \mathrm{O}$, after completion of the reaction in the first run, the catalyst was isolated using an external magnet (Figure S1a,b), washed with EtOAc and $\mathrm{EtOH}(2 \times 10 \mathrm{~mL})$, and dried under vacuum. The

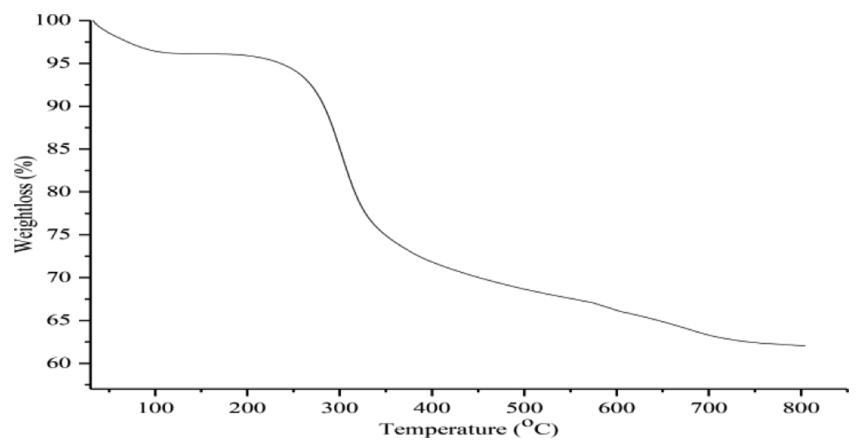

Figure 6. TGA of $\mathrm{Fe}_{3} \mathrm{O}_{4} @ \mathrm{CS}-\mathrm{Co}$.

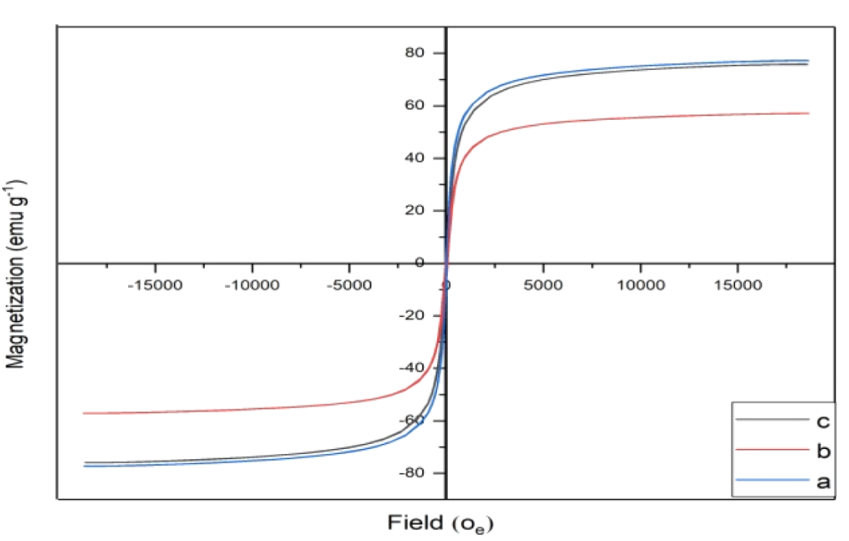

Figure 7. Magnetic hysteresis curves of (a) $\mathrm{Fe}_{3} \mathrm{O}_{4} \mathrm{NPs}$, (b) $\mathrm{Fe}_{3} \mathrm{O}_{4} @$ $\mathrm{CS}$, and (c) $\mathrm{Fe}_{3} \mathrm{O}_{4} @$ @S-Co.

catalyst was successfully recycled five times. Loss of catalytic activity was not considerably observed for $\mathrm{Fe}_{3} \mathrm{O}_{4} @ \mathrm{CS}$-Co in these reactions (Figure S1c). Comparison of FT-IR spectrum of the reused catalyst (Figure S1d) with that of the freshly prepared one (Figure S1d) indicated that no significant 

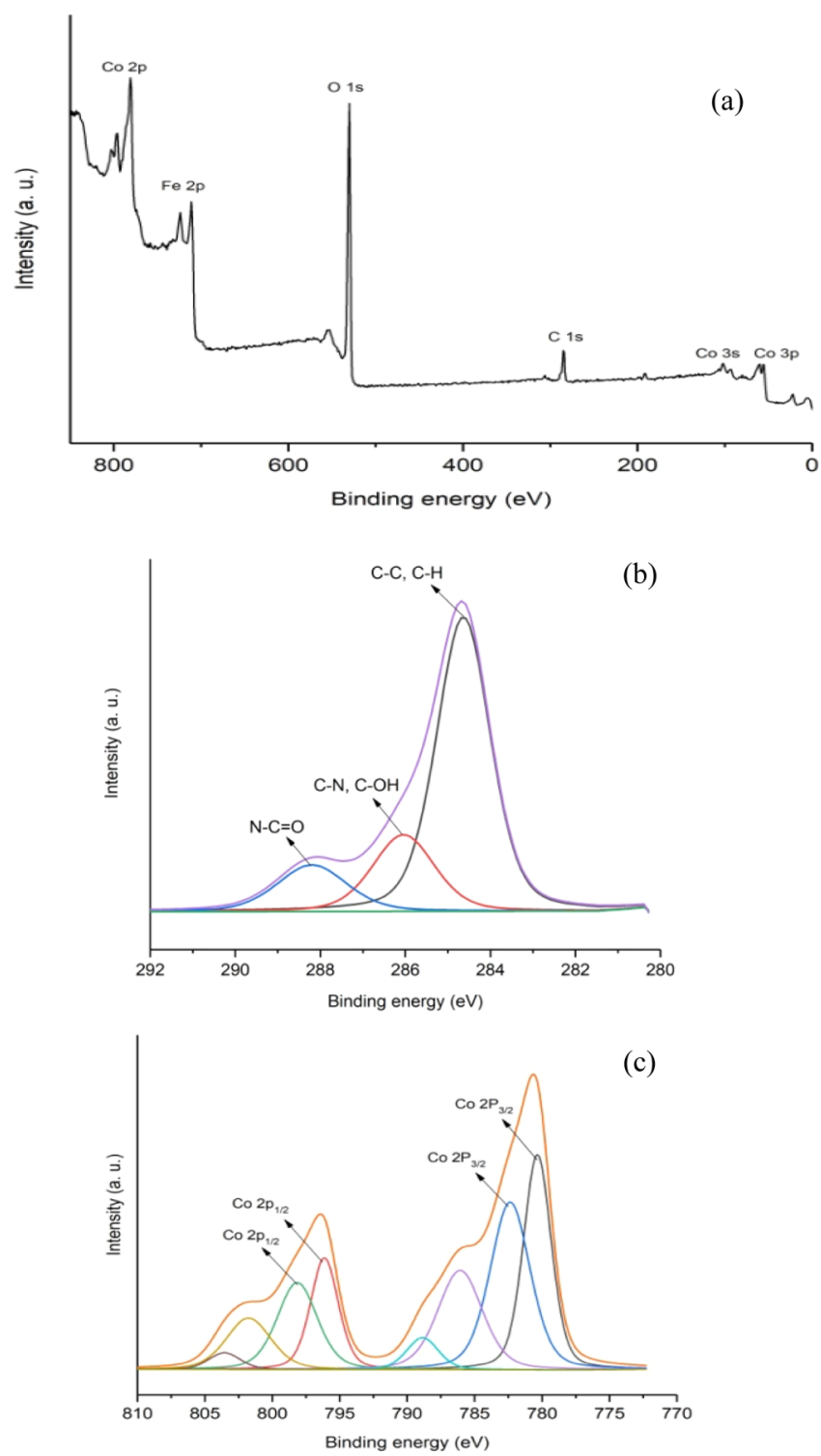

Figure 8. XPS deconvolutions of (a) $\mathrm{Fe}_{3} \mathrm{O}_{4} @$ CS-Co, (b) C 1s, and (c) cobalt.
Table 2. Cyanation Reaction of Various Aryl Halides in the Presence of $\mathrm{K}_{4} \mathrm{Fe}(\mathrm{CN})_{6} \cdot 3 \mathrm{H}_{2} \mathrm{O}$ Catalyzed by $\mathrm{Fe}_{3} \mathrm{O}_{4} @ \mathrm{CS}-\mathrm{Co}$.

$$
\mathrm{Ar}-\mathrm{X}+\mathrm{K}_{4}\left[\mathrm{Fe}(\mathrm{CN})_{6}\right] \cdot 3 \mathrm{H}_{2} \mathrm{O} \frac{\mathrm{Fe}_{3} \mathrm{O}_{4} @ \mathrm{CS}-\mathrm{Co}(5 \mathrm{~mol} \%)}{\mathrm{Et}_{3} \mathrm{~N}, 100^{\circ} \mathrm{C}, \mathrm{DMF}} \mathrm{Ar}-\mathrm{CN}
$$

\begin{tabular}{cllcc} 
entry & \multicolumn{1}{c}{$\mathrm{Ar}$} & $\mathrm{X}$ & time $(\mathrm{h})$ & yield $^{a}(\%)$ \\
1 & $\mathrm{Ph}$ & $\mathrm{I}$ & 8 & 85 \\
2 & $4-\mathrm{I}-\mathrm{C}_{6} \mathrm{H}_{4}$ & $\mathrm{I}$ & 12 & 72 \\
3 & $4-(\mathrm{MeO})-\mathrm{C}_{6} \mathrm{H}_{4}$ & $\mathrm{I}$ & 10 & 85 \\
4 & $\mathrm{Ph}$ & $\mathrm{Br}$ & 9 & 82 \\
5 & $4-\left(\mathrm{NO}_{2}\right)-\mathrm{C}_{6} \mathrm{H}_{4}$ & $\mathrm{Br}$ & 12 & 73 \\
6 & $4-(\mathrm{CN})-\mathrm{C}_{6} \mathrm{H}_{4}$ & $\mathrm{Br}$ & 12 & 80 \\
7 & $4-\mathrm{Me}-\mathrm{C}_{6} \mathrm{H}_{4}$ & $\mathrm{Br}$ & 13 & 64 \\
8 & $4-\mathrm{F}-\mathrm{C}_{6} \mathrm{H}_{4}$ & $\mathrm{Br}$ & 15 & 68 \\
9 & $3-\mathrm{pyridyl}$ & $\mathrm{Br}$ & 11 & 85 \\
10 & $\mathrm{Ph}$ & $\mathrm{Cl}$ & 14 & 76 \\
11 & $\left.4-(\mathrm{NO})_{2}\right)-\mathrm{C}_{6} \mathrm{H}_{4}$ & $\mathrm{Cl}$ & 13 & 65 \\
12 & $4-(\mathrm{CN})-\mathrm{C}_{6} \mathrm{H}_{4}$ & $\mathrm{Cl}$ & 12 & 71 \\
13 & $4-\mathrm{Me}-\mathrm{C}_{6} \mathrm{H}_{4}$ & $\mathrm{Cl}$ & 15 & 60 \\
14 & $4-(\mathrm{CHO})-\mathrm{C}_{6} \mathrm{H}_{4}$ & $\mathrm{Cl}$ & 24 & 82
\end{tabular}

${ }^{a}$ Reaction conditions: $100{ }^{\circ} \mathrm{C}$, iodobenzene $(1 \mathrm{mmol}), \mathrm{K}_{4} \mathrm{Fe}(\mathrm{CN})_{6}$. $3 \mathrm{H}_{2} \mathrm{O}(1.5 \mathrm{mmol}), \mathrm{Et}_{3} \mathrm{~N}(4 \mathrm{mmol})$, and DMF $(5 \mathrm{~mL})$. Mean $\pm(1-$ $6 \%)$ standard deviation (replicates $=4)$.

changes in the chemical structure of the catalyst were observed. Moreover, FE-SEM and TEM images illustrated that the nanoparticles were still spherical in shape even after 5th cycle reuse (Figure S1e,f), and the mean diameter size of the recycled catalyst was $19 \mathrm{~nm}$ (Figure $\mathrm{S} 1 \mathrm{~g}$ ).

The heterogeneous character of $\mathrm{Fe}_{3} \mathrm{O}_{4} @ \mathrm{CS}$-Co was checked by hot filtration. For this purpose, at half time of the reaction of iodobenzene in the presence of $\mathrm{K}_{4}\left[\mathrm{Fe}(\mathrm{CN})_{6}\right] \cdot 3 \mathrm{H}_{2} \mathrm{O}(4 \mathrm{~h}$ approx.), the catalyst was isolated using an external magnetic field from the reaction mixture, and the reaction was then allowed to continue without any catalyst. No additional product formation was observed after $9 \mathrm{~h}$, which clearly indicated the heterogeneous character of $\mathrm{Fe}_{3} \mathrm{O}_{4} @ \mathrm{CS}-\mathrm{Co}$ (Figure 9b). The heterogeneous character of $\mathrm{Fe}_{3} \mathrm{O}_{4} @ C S-\mathrm{Co}$ was also evaluated after a poisoning test using $S_{8}$ as a metal trap. This test was conducted for the aforementioned model reaction in the presence of $S_{8}(0.05 \mathrm{~g})$. No considerable changes were observed in the progress of the reaction (Figure

Table 1. Optimization of the Reaction Conditions for the Cyanation Reaction of Iodobenzene

\begin{tabular}{|c|c|c|c|c|c|c|c|}
\hline entry & catalyst (mol \%) & source of $\mathrm{CN}$ & base & solvent & $T\left({ }^{\circ} \mathrm{C}\right)$ & time $(\mathrm{h})$ & isolated yield ${ }^{a}(\%)$ \\
\hline 1 & 5 & $\mathrm{~K}_{4} \mathrm{Fe}(\mathrm{CN})_{6}$ & $\mathrm{Et}_{3} \mathrm{~N}$ & DMF & 100 & 8 & 85 \\
\hline 2 & 5 & $\mathrm{KCN}$ & $\mathrm{Et}_{3} \mathrm{~N}$ & DMF & 100 & 7 & 85 \\
\hline 3 & 5 & $\mathrm{Me}_{3} \mathrm{SiCN}$ & $\mathrm{Et}_{3} \mathrm{~N}$ & DMF & 100 & 24 & $c$ \\
\hline 4 & 5 & $\mathrm{Me}_{3} \mathrm{SiCN}$ & $\mathrm{Et}_{3} \mathrm{~N}$ & & 75 & 5 & 50 \\
\hline 5 & 5 & $\mathrm{~K}_{4} \mathrm{Fe}(\mathrm{CN})_{6}$ & $\mathrm{Et}_{3} \mathrm{~N}$ & $\mathrm{EtOH}$ & $b$ & 24 & $c$ \\
\hline 6 & 5 & $\mathrm{~K}_{4} \mathrm{Fe}(\mathrm{CN})_{6}$ & $\mathrm{Et}_{3} \mathrm{~N}$ & $\mathrm{H}_{2} \mathrm{O}$ & 90 & 3 & 35 \\
\hline 7 & 5 & $\mathrm{~K}_{4} \mathrm{Fe}(\mathrm{CN})_{6}$ & $\mathrm{Et}_{3} \mathrm{~N}$ & DMSO & $b$ & 2 & 30 \\
\hline 8 & 5 & $\mathrm{~K}_{4} \mathrm{Fe}(\mathrm{CN})_{6}$ & $\mathrm{Et}_{3} \mathrm{~N}$ & DMF & 25 & 7 & 37 \\
\hline 9 & 5 & $\mathrm{~K}_{4} \mathrm{Fe}(\mathrm{CN})_{6}$ & $\mathrm{~K}_{2} \mathrm{CO}_{3}$ & DMF & 100 & 6 & 42 \\
\hline 10 & 5 & $\mathrm{~K}_{4} \mathrm{Fe}(\mathrm{CN})_{6}$ & $\mathrm{NaOEt}$ & DMF & 100 & 6.5 & 32 \\
\hline 11 & 3 & $\mathrm{~K}_{4} \mathrm{Fe}(\mathrm{CN})_{6}$ & $\mathrm{Et}_{3} \mathrm{~N}$ & DMF & 100 & 9 & 73 \\
\hline 12 & 1 & $\mathrm{~K}_{4} \mathrm{Fe}(\mathrm{CN})_{6}$ & $\mathrm{Et}_{3} \mathrm{~N}$ & DMF & 100 & 10 & 64 \\
\hline 13 & & $\mathrm{~K}_{4} \mathrm{Fe}(\mathrm{CN})_{6}$ & $\mathrm{Et}_{3} \mathrm{~N}$ & DMF & 100 & 24 & $c$ \\
\hline $14^{d}$ & 5 & $\mathrm{~K}_{4} \mathrm{Fe}(\mathrm{CN})_{6}$ & $\mathrm{Et}_{3} \mathrm{~N}$ & DMF & 100 & 24 & 20 \\
\hline
\end{tabular}

${ }^{a}$ Reaction conditions: iodobenzene $(1 \mathrm{mmol})$, cyanide source $(1.5 \mathrm{mmol})$, base $(4 \mathrm{mmol})$, and solvent $(5 \mathrm{~mL}) .{ }^{b}$ Under reflux conditions. ${ }^{c}$ Trace amount. ${ }^{d} \mathrm{CoCl}_{2} \cdot 4 \mathrm{H}_{2} \mathrm{O}$. 


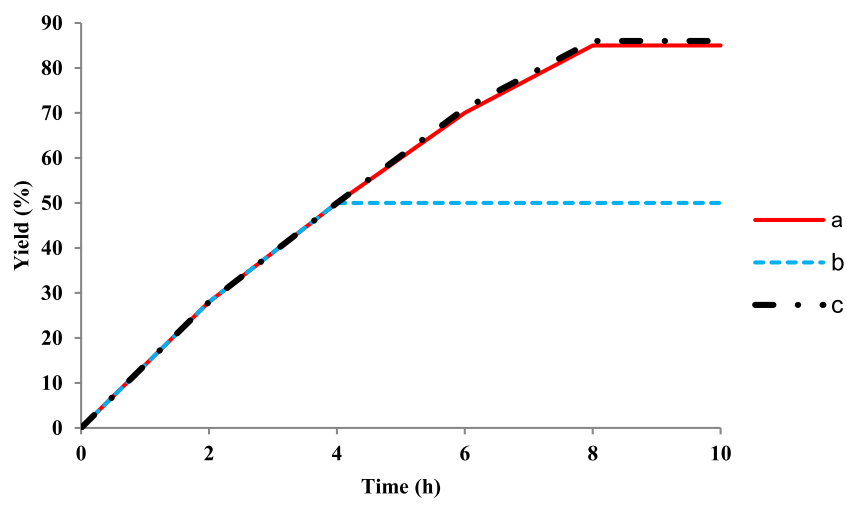

Figure 9. Reaction kinetics of (a) standard reaction of iodobenzene and $\mathrm{K}_{4}\left[\mathrm{Fe}(\mathrm{CN})_{6}\right] \cdot 3 \mathrm{H}_{2} \mathrm{O}$ catalyzed by $\mathrm{Fe}_{3} \mathrm{O}_{4} @ \mathrm{CS}-\mathrm{Co}$ in DMF at 100 ${ }^{\circ} \mathrm{C}$, (b) high temperature filtration test, and (c) poisoning test using $\mathrm{S}_{8}$.

9c). The results of these two tests showed that $\mathrm{Fe}_{3} \mathrm{O}_{4} @ \mathrm{CS}-\mathrm{Co}$ was truly heterogeneous in this process.

To study the synthetic applications and scope of this protocol, the reaction of iodobenzene $(50 \mathrm{mmol})$ and $\mathrm{K}_{4}\left[\mathrm{Fe}(\mathrm{CN})_{6}\right] \cdot 3 \mathrm{H}_{2} \mathrm{O}(75 \mathrm{mmol})$ was assessed under the optimized reaction conditions, and the desired product was isolated in $80 \%$ yield after $15 \mathrm{~h}$.

2.3. Hiyama Cross-Coupling Reaction between Aryl Halides and Triethoxyphenylsilane Promoted by $\mathrm{Fe}_{3} \mathrm{O}_{4} @ \mathrm{CS}-\mathrm{Co}$. Encouraged by the results obtained during the cyanation of arylhalides catalyzed by $\mathrm{Fe}_{3} \mathrm{O}_{4} @ \mathrm{CS}-\mathrm{Co}$ and the success of mTEG-CS-Co-Schiff base as the first cobalt catalyst in the Hiyama reaction, ${ }^{30}$ we investigated the catalytic reactivity of $\mathrm{Fe}_{3} \mathrm{O}_{4} @ \mathrm{CS}-\mathrm{Co}$ in the Hiyama cross-coupling reaction. In this regard, one-pot reaction of iodobenzene with triethoxyphenylsilane was selected to optimize the reaction conditions. As the nature of the base is important for the Hiyama reaction, some bases such as $\mathrm{NaOH}, \mathrm{Et}_{3} \mathrm{~N}, \mathrm{~K}_{2} \mathrm{CO}_{3}$, and $\mathrm{NaF}$ (also as an activator of the organosilane) were tested for this reaction in the presence of $1 \mathrm{~mol} \%$ of $\mathrm{Fe}_{3} \mathrm{O}_{4} @ \mathrm{CS}-\mathrm{Co}$ at $100{ }^{\circ} \mathrm{C}$ (Table 3, entries 1-4). Among the bases examined, $\mathrm{Et}_{3} \mathrm{~N}$ was the most appropriate base (Table 3, entry 2). When

Table 3. Optimization of the Reaction Conditions for Hiyama Cross-Coupling Reaction of Iodobenzene with Triethoxyphenylsilane

\begin{tabular}{ccllccc} 
entry & $\begin{array}{c}\text { catalyst } \\
(\mathrm{mol} \%)\end{array}$ & base & solvent & $T\left({ }^{\circ} \mathrm{C}\right)$ & $\begin{array}{c}\text { time } \\
(\mathrm{h})\end{array}$ & $\begin{array}{c}\text { yield }^{a} \\
(\%)\end{array}$ \\
\hline 1 & 1 & $\mathrm{NaOH}$ & $\mathrm{DMF}$ & 100 & 8 & 30 \\
2 & 1 & $\mathrm{Et}_{3} \mathrm{~N}$ & $\mathrm{DMF}$ & 100 & 4.5 & 73 \\
3 & 1 & $\mathrm{~K}_{2} \mathrm{CO}_{3}$ & $\mathrm{DMF}$ & 100 & 5 & $c$ \\
4 & 1 & $\mathrm{NaF}$ & $\mathrm{DMF}$ & 100 & 6 & $c$ \\
5 & 1 & $\mathrm{Et}_{3} \mathrm{~N}$ & $\mathrm{EtOH}$ & $b$ & 4 & 45 \\
6 & 1 & $\mathrm{Et}_{3} \mathrm{~N}$ & $\mathrm{EtOAc}$ & $b$ & 5 & 33 \\
7 & 1 & $\mathrm{Et}_{3} \mathrm{~N}$ & $\mathrm{CH}{ }_{3} \mathrm{CN}$ & $b$ & 24 & $c$ \\
8 & 1 & $\mathrm{Et}_{3} \mathrm{~N}$ & $\mathrm{H}_{2} \mathrm{O}$ & 100 & 4.5 & 47 \\
9 & 1 & $\mathrm{Et}_{3} \mathrm{~N}$ & $\mathrm{DMF}$ & 50 & 5 & 33 \\
10 & 1 & $\mathrm{Et}_{3} \mathrm{~N}$ & $\mathrm{DMF}$ & $\mathrm{r} . \mathrm{H}$ & 7 & $c$ \\
11 & 0.5 & $\mathrm{Et}_{3} \mathrm{~N}$ & $\mathrm{DMF}$ & 100 & 5 & 60 \\
12 & 2 & $\mathrm{Et}_{3} \mathrm{~N}$ & $\mathrm{DMF}$ & 100 & 3 & 91
\end{tabular}

${ }^{a}$ Isolated yield; reaction conditions: iodobenzene (1 $\left.\mathrm{mmol}\right)$, triethoxyphenylsilane $(1.1 \mathrm{mmol})$, base $(2 \mathrm{mmol})$, and solvent $(5$ $\mathrm{mL}) .{ }^{b}$ Under reflux conditions. ${ }^{c}$ Trace amount of the product was obtained.
$\mathrm{NaF}$ was used as the base, just a trace amount of the product was produced (Table 3, entry 4). During the solvent screening (Table 3, entries 5-8), we found that the best result was obtained in DMF (Table 3, entry 2). The benchmark reaction was performed at different temperatures (Table 3, entries 9, 10 ), and the best catalytic activity was detected at $100{ }^{\circ} \mathrm{C}$ (Table 3, entry 2). The reaction was also studied using different catalyst loadings (Table 3, entries 11 and 12), concluding that the reaction proceeded with $2 \mathrm{~mol} \%$ of the catalyst (Table 3 , entry 12 ).

The generality of this protocol for the fluoride-free Hiyama reaction of a variety of substituted aryl halides and triethoxyphenylsilane under the optimized reaction conditions was investigated. As depicted in Table 4, various aryl halides

Table 4. Hiyama Cross-Coupling Reaction between Various Aryl Halides and Triethoxyphenylsilane Promoted by $\mathrm{Fe}_{3} \mathrm{O}_{4} @ \mathrm{CS}-\mathrm{Co}$.

$$
\mathrm{Ar}-\mathrm{X}+\mathrm{Ar}-\mathrm{Si}(\mathrm{OEt})_{3} \frac{\mathrm{Fe}_{3} \mathrm{O}_{4} @ \mathrm{CS}-\mathrm{Co}(2 \mathrm{~mol} \%)}{\mathrm{Et}_{3} \mathrm{~N}, 100^{\circ} \mathrm{C}, \mathrm{DMF}} \mathrm{Ar}-\mathrm{Ar}^{\prime}
$$

\begin{tabular}{cllcc} 
entry & \multicolumn{1}{c}{$\mathrm{Ar}$} & $\mathrm{X}$ & time $(\mathrm{h})$ & yield $^{a}(\%)$ \\
1 & $\mathrm{Ph}$ & $\mathrm{I}$ & 3 & 91 \\
2 & $4-(\mathrm{MeO})-\mathrm{C}_{6} \mathrm{H}_{4}$ & $\mathrm{I}$ & 7 & 74 \\
3 & $\mathrm{Ph}$ & $\mathrm{Br}$ & 5 & 90 \\
4 & $4-(\mathrm{MeO})-\mathrm{C}_{6} \mathrm{H}_{4}$ & $\mathrm{Br}$ & 6 & 85 \\
5 & $4-\left(\mathrm{NO}_{2}\right)-\mathrm{C}_{6} \mathrm{H}_{4}$ & $\mathrm{Br}$ & 4.5 & 89 \\
6 & $4-(\mathrm{CN})-\mathrm{C}_{6} \mathrm{H}_{4}$ & $\mathrm{Br}$ & 5 & 88 \\
7 & $\mathrm{Ph}$ & $\mathrm{Cl}$ & 7 & 85 \\
8 & $\left.4-(\mathrm{NO})_{2}\right)-\mathrm{C}_{6} \mathrm{H}_{4}$ & $\mathrm{Cl}$ & 6 & 76 \\
9 & $4-(\mathrm{CN})-\mathrm{C}_{6} \mathrm{H}_{4}$ & $\mathrm{Cl}$ & 6.5 & 83 \\
10 & $4-\mathrm{Cl}-\mathrm{C}_{6} \mathrm{H}_{4}$ & $\mathrm{I}$ & 3 & 74 \\
11 & $4-\mathrm{Cl}-\mathrm{C}_{6} \mathrm{H}_{4}$ & $\mathrm{Br}$ & 4 & 85 \\
12 & $4-\mathrm{I}-\mathrm{C}_{6} \mathrm{H}_{4}$ & $\mathrm{I}$ & 7 & 62
\end{tabular}

${ }^{a}$ Reaction conditions: aryl halide $(1 \mathrm{mmol})$, triethoxyphenylsilane $(1.1 \mathrm{mmol}), \mathrm{Et}_{3} \mathrm{~N}(2 \mathrm{mmol}), \mathrm{DMF}(5 \mathrm{~mL})$, and catalyst $(2 \mathrm{~mol} \%)$ at $100{ }^{\circ} \mathrm{C}$. Mean $\pm(1-6 \%)$ standard deviation (number of replicates $=$ $3)$.

(iodides, bromides, and chlorides) having electron-withdrawing and electron-donating groups reacted satisfactorily with triethoxyphenylsilane, and the desired products were obtained in $62-91 \%$ yields (Table 4 , entries $1-9$ ). Moreover, 1-chloro-4-iodobenzene, 1-bromo-4-chlorobenzene, and 1,4diiodobenzene chemoselectively furnished 4-chlorobiphenyl and 4-iodobiphenyl as the only products in 74,85 , and $62 \%$ yields, respectively (Table 4, entries 10-12).

The recyclability of the catalyst $\left(\mathrm{Fe}_{3} \mathrm{O}_{4} @ \mathrm{CS}-\mathrm{Co}\right)$ was studied in the reaction of iodobenzene with triethoxyphenylsilane under optimized reaction conditions. After $3 \mathrm{~h}$, the reaction mixture was cooled to ambient temperature, and the catalyst was isolated using an external magnet, washed with EtOAc and $\mathrm{EtOH}(2 \times 10 \mathrm{~mL})$, dried in vacuum, and recycled again. As exhibited in Figure S2, the catalyst was recycled in five consecutive runs without any important loss in activity.

The products in the present work have broad applications as fundamental building blocks in the synthesis of various molecules having different structures in numerous fields of chemistry such as pharmaceuticals and materials sciences. For instance, biaryl segments (products of Hiyama reaction) and aryl nitriles (products of cyanation reaction) are the common scaffold of a number of interesting drugs such as flurbiprofen (inflammatory agent), biphenyl-4-carboxylic acid hydrazide- 
Scheme 2. Structure of Some Biological Compounds Containing Arylnitrile or Biaryl Moieties

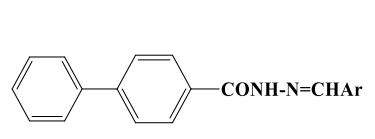

biphenyl-4-carboxylic acid hydrazide-hydrazone

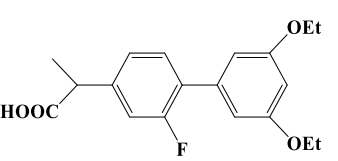

Flurbiprofen

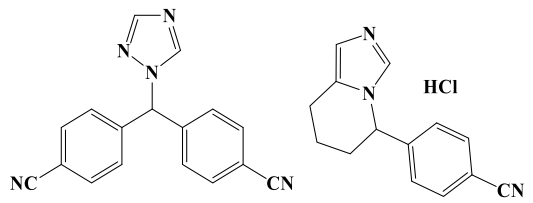

Letrozole

Fadrozole mono hydrochloride

hydrazone (antimicrobial), letrozole as an inhibitor for the treatment of hormonally responsive breast cancer, and fadrozole monohydrochloride useful for the treatment of breast cancer (Scheme 2). ${ }^{32}$

\section{CONCLUSIONS}

In this paper, we have synthesized Co NPs immobilized on nanomagnetic chitosan $\left(\mathrm{Fe}_{3} \mathrm{O}_{4} @ \mathrm{CS}-\mathrm{Co}\right)$ and identified it using different techniques such as FT-IR, XRD, FE-SEM, EDX, TEM, TGA, VSM, XPS, and ICP-AES analysis. This catalyst was efficiently used as a new nanomagnetic heterogeneous cobalt catalyst in the cyanation reaction and in the fluoride-free Hiyama coupling between various substituted aryl chlorides, bromides, and iodides with $\mathrm{K}_{4}[\mathrm{Fe}$ $\left.(\mathrm{CN})_{6}\right] \cdot 3 \mathrm{H}_{2} \mathrm{O}$ or triethoxyphenylsilane, respectively. The results of hot filtration and poisoning tests revealed that the catalyst was truly heterogeneous in nature. The catalyst was separated using an external magnet and recycled for at least five times without serious loss in activity. The use of an inexpensive cobalt catalyst instead of a high-cost palladium catalyst, without the employment of toxic ligands or fluoride ions, with $\mathrm{K}_{4}\left[\mathrm{Fe}(\mathrm{CN})_{6}\right] \cdot 3 \mathrm{H}_{2} \mathrm{O}$ as an inexpensive cyanide source, the ease of recovery and reusability of the catalyst, and applicability of the method for large-scale usage are the main advantages of this protocol. It is worth to note that, in this paper, the cobalt catalyst has been used for the first time for the cyanation of arylhalides.

\section{EXPERIMENTAL SECTION}

4.1. General Procedure for the Synthesis of Magnetic Chitosan $\left(\mathrm{Fe}_{3} \mathrm{O}_{4} @ \mathrm{CS}\right)$. $^{33}$ A solution of chitosan (1 g) in acetic acid $(100 \mathrm{~mL}, 2 \%)$ was sonicated for 0.5 h. $\mathrm{Fe}_{3} \mathrm{O}_{4}$ nanoparticles $(1.7 \mathrm{~g})$ were added to the sonicated solution and stirred for $1 \mathrm{~h}$. Then, the mixture was neutralized by adding aqueous solution of $\mathrm{NaOH}(8 \mathrm{~mL}, 1.66 \mathrm{M})$ dropwise and stirred for $1 \mathrm{~h}$ at ambient temperature. The resulting $\mathrm{Fe}_{3} \mathrm{O}_{4} @$ $\mathrm{CS}$ was separated using an external magnet, washed using $\mathrm{H}_{2} \mathrm{O}$ and $\mathrm{EtOH}(3 \times 20 \mathrm{~mL})$, and dried under vacuum at $60{ }^{\circ} \mathrm{C}$.

4.2. General Procedure for the Synthesis of $\mathrm{Fe}_{3} \mathrm{O}_{4} @$ CS-Co. $\mathrm{Fe}_{3} \mathrm{O}_{4} @ \mathrm{CS}(1 \mathrm{~g})$ was dispersed by sonication in $\mathrm{H}_{2} \mathrm{O}$ $(25 \mathrm{~mL})$. To this mixture, an aqueous solution of cobalt(II) chloride $(25 \mathrm{~mL}, 10 \mathrm{M})$ was added dropwise under vigorous stirring. After $2 \mathrm{~h}$, an aqueous solution of $\mathrm{NaBH}_{4}(5 \mathrm{mmol}$ in $15 \mathrm{~mL}$ ) was added slowly to this mixture. After $20 \mathrm{~min}$, $\mathrm{Fe}_{3} \mathrm{O}_{4} @ \mathrm{CS}-\mathrm{Co}$ was isolated using an external magnet and washed with $\mathrm{H}_{2} \mathrm{O}$ and $\mathrm{EtOH}(3 \times 20 \mathrm{~mL})$ and dried under vacuum at $40{ }^{\circ} \mathrm{C}$.

4.3. General Procedure for the Cyanation Reaction of Aryl Halides with $\mathrm{K}_{4}\left[\mathrm{Fe}(\mathrm{CN})_{6}\right] \cdot 3 \mathrm{H}_{2} \mathrm{O}$ Catalyzed by $\mathrm{Fe}_{3} \mathrm{O}_{4} @ \mathrm{CS}-\mathrm{Co} . \mathrm{Fe}_{3} \mathrm{O}_{4} @ \mathrm{CS}-\mathrm{Co}(5 \mathrm{~mol} \%)$ was added to a mixture formed by $\mathrm{K}_{4}\left[\mathrm{Fe}(\mathrm{CN})_{6}\right] \cdot 3 \mathrm{H}_{2} \mathrm{O}(1.5 \mathrm{mmol})$, the aryl halide $(1 \mathrm{mmol})$, and $\mathrm{Et}_{3} \mathrm{~N}(4 \mathrm{mmol})$ in $\operatorname{DMF}(5 \mathrm{~mL})$ and stirred at $100{ }^{\circ} \mathrm{C}$. After the time indicated in Table 2, the reaction mixture was cooled to ambient temperature, and $\mathrm{Fe}_{3} \mathrm{O}_{4} @ \mathrm{CS}-\mathrm{Co}$ was isolated using an external magnet, washed with $\mathrm{H}_{2} \mathrm{O}$ and $\mathrm{EtOH}(2 \times 10 \mathrm{~mL})$, dried in vacuum, and recycled again. The purification of the product was done by column chromatography on silica gel using $n$-hexane/EtOAc $(6: 1)$ as the eluent.

4.4. General Procedure for the Hiyama CrossCoupling Reaction of Aryl Halides with Triethoxyphenylsilane Catalyzed by $\mathrm{Fe}_{3} \mathrm{O}_{4} @ \mathrm{CS}-\mathrm{Co} . \mathrm{Fe}_{3} \mathrm{O}_{4} @ \mathrm{CS}-\mathrm{Co}(2$ mol \%) was added to a mixture containing triethoxyphenylsilane $(1.1 \mathrm{mmol})$, aryl halide $(1 \mathrm{mmol})$, and $\mathrm{Et}_{3} \mathrm{~N}(2 \mathrm{mmol})$ in DMF $(5 \mathrm{~mL})$, and the mixture was stirred at $100{ }^{\circ} \mathrm{C}$. After the time indicated in Table 4, the reaction mixture was cooled to ambient temperature, and $\mathrm{Fe}_{3} \mathrm{O}_{4} @ \mathrm{CS}$-Co was isolated using an external magnet, washed with EtOAc and EtOH $(2 \times 10 \mathrm{~mL})$, dried under vacuum, and recycled again. The purification of the product was done by column chromatography on silica gel using $n$-hexane/EtOAc (50:1) as the eluent.

\section{ASSOCIATED CONTENT}

\section{Supporting Information}

The Supporting Information is available free of charge at https://pubs.acs.org/doi/10.1021/acsomega.0c01002.

General information on the instruments, analysis of the reused catalyst, and ${ }^{1} \mathrm{H}$ NMR and ${ }^{13} \mathrm{C}$ NMR spectra of the products $(\mathrm{PDF})$

\section{AUTHOR INFORMATION}

\section{Corresponding Author}

Sara Sobhani - Department of Chemistry, College of Sciences, University of Birjand, Birjand 9717434765, Iran; (1) orcid.org/0000-0002-7764-8847; Phone: +98 56 32202065; Email: ssobhani@birjand.ac.ir, sobhanisara@ yahoo.com; Fax: +98 5632202065

\section{Authors}

Hadis Hosseini Moghadam - Department of Chemistry, College of Sciences, University of Birjand, Birjand 9717434765, Iran

José Miguel Sansano - Departamento de Química Orgánica, Facultad de Ciencias, Centro de Innovación en Quimica Avanzada (ORFEO-CINQA) and Instituto de Sintesis Orgánica (ISO), Universidad de Alicante, Alicante 03080, Spain; ○ orcid.org/0000-0002-5536-2717

Complete contact information is available at: https://pubs.acs.org/10.1021/acsomega.0c01002

\section{Notes}

The authors declare no competing financial interest. 


\section{ACKNOWLEDGMENTS}

Financial support for this project from the University of Birjand Research Council is acknowledged. Access to the XPS facilities of the Central Technical Services of the University of Alicante is appreciated.

\section{REFERENCES}

(1) (a) Sokolová, R.; Hromadová, M.; Fiedler, J.; Pospísil, L.; Giannarelli, S.; Valášek, M. Reduction of substituted benzonitrile pesticides. J. Electroanal. Chem. 2008, 622, 211-218. (b) Patel, A. B.; Chikhalia, K. H.; Kumari, P. Facile synthesis of benzonitrile/ nicotinonitrile based s-triazines as new potential antimycobacterial agents. Eur. J. Med. Chem. 2014, 79, 57-65. (c) Fouda, A. S.; El-Azaly, A. H.; Awad, R. S.; Ahmed, A. M. New benzonitrile azo Dyes as corrosion inhibitors for carbon steel in hydrochloric acid solutions. Int. J. Electrochem. Sci. 2014, 9, 1117-1131. Anbarasan, P.; Neumann, H.; Beller, M. A novel and convenient synthesis of benzonitrililes: electrophilic cyanation of aryl and heteroaryl bromides. Chem.-Eur. J. 2011, 17, 4217-4222.

(2) Yan, G.; Zhang, Y.; Wang, J. Recent advances in the synthesis of aryl nitrile compounds. Adv. Synth. Catal. 2017, 359, 4068-4105.

(3) (a) Rapolu, C. S. R.; Panja, K. R. Highly selective V-P-O/ $\gamma$ $\mathrm{Al}_{2} \mathrm{O}_{3}$ catalysts in the ammoxidation of toluene to benzonitrile. $J$. Chem. Soc., Chem. Commun. 1993, 1175-1176. (b) Koelsch, C. F.; Whitney, A. G. The Rosenmund-von Braun nitrile synthesis. J. Org. Chem. 1941, 06, 795-803. (c) Beletskaya, I. P.; Sigeev, A. S.; Peregudov, A. S.; Petrovskii, P. V. Catalytic Sandmeyer cyanation as a synthetic pathway to aryl nitriles. J. Organomet. Chem. 2004, 689, $3810-3812$.

(4) Yeung, P. Y.; So, C. M.; Lau, C. P.; Kwong, F. Y. A mild and efficient palladium-catalyzed cyanation of aryl chlorides with $\mathrm{K}_{4}[\mathrm{Fe}-$ $(\mathrm{CN})_{6}$ ]. Org. Lett. 2011, 13, 648-651.

(5) (a) Khajeh Dangolani, S.; Sharifat, S.; Panahi, F.; KhalafiNezhad, A. Immobilized palladium nanoparticles on a cyclodextrinpolyurethane nanosponge (Pd-CD-PU-NS): An efficient catalyst for cyanation reaction in aqueous media. Inorg. Chim. Acta 2019, 494, 256-265. (b) Zou, T.; Yu, X.; Feng, X.; Bao, M. An efficient transformation of primary halides into nitriles through palladiumcatalyzed hydrogen transfer reaction. Chem. Commun. 2015, 51, 10714-10717.

(6) Ueda, Y.; Tsujimoto, N.; Yurino, T.; Tsurugi, H.; Mashima, K. Nickel-catalyzed cyanation of aryl halides and triflates using acetonitrile via $\mathrm{C}-\mathrm{CN}$ bond cleavage assisted by 1,4-bis(trimethylsilyl)-2,3,5,6-tetramethyl-1,4-dihydropyrazine. Chem. Sci. 2019, 10, 994-999.

(7) Khemnar, A. B.; Sawant, D. N.; Bhanage, B. M. Rhodium catalyzed cyanide-free cyanation of aryl halide by using formamide as a cyanide source. Tetrahedron Lett. 2013, 54, 2682-2684.

(8) Liskey, C. W.; Liao, X.; Hartwig, J. F. Cyanation of arenes via Iridium-catalyzed borylation. J. Am. Chem. Soc. 2010, 132, 1138911391.

(9) Khemnar, A. B.; Bhanage, B. M. Copper catalyzed nitrile synthesis from aryl halides using formamide as a nitrile source. RSC Adv. 2014, 4, 13405-13408.

(10) (a) Arvela, R. K.; Leadbeater, N. E.; Torenius, H. M.; Tye, H. Rapid cyanation of aryl iodides in water using microwave promotion. Org. Biomol. Chem. 2003, 1, 1119-1121. (b) Sundermeier, M.; Zapf, A.; Beller, M.; Sans, J. A new palladium catalyst system for the cyanation of aryl chlorides. Tetrahedron Lett. 2001, 42, 6707-6710. (c) Maligres, P. E.; Waters, M. S.; Fleitz, F.; Askin, D. A highly catalytic robust palladium catalyzed cyanation of aryl bromides. Tetrahedron Lett. 1999, 40, 8193-8195. (d) Sundermeier, M.; Mutyala, S.; Zapf, A.; Spannenberg, A.; Beller, M. A convenient and efficient procedure for the palladium-catalyzed cyanation of aryl halides using trimethylsilylcyanide. J. Organomet. Chem. 2003, 684, $50-55$.

(11) (a) Veisi, H. Efficient cyanation of aryl halides with $\mathrm{K}_{4}\left[\mathrm{Fe}(\mathrm{CN})_{6}\right]$ catalyzed by encapsulated palladium nanoparticles in biguanidine-chitosan matrix as core-shell recyclable heterogeneous nanocatalyst. Polyhedron 2019, 159, 212-216. (b) Karimi, B.; Vafaeezadeh, M.; Akhavan, P. F. N-Heterocyclic Carbene-Pd Polymers as Reusable Precatalysts for Cyanation and Ullmann Homocoupling of Aryl Halides: The Role of Solvent in Product Distribution. Chem CatChem 2015, 7, 2248-2254.

(12) Ganapathy, D.; Kotha, S. S.; Sekar, G. Stable palladium nanoparticles catalyzed synthesis of benzonitriles using $\mathrm{K}_{4}\left[\mathrm{Fe}(\mathrm{CN})_{6}\right]$. Tetrahedron Lett. 2015, 56, 175-178.

(13) (a) Jeong, E.; Lee, W. R.; Ryu, D. W.; Kim, Y.; Phang, W. J.; Koh, E. K.; Hong, C. S. Reversible structural transformation and selective gas adsorption in a unique aqua-bridged Mn (II) metal organic framework. Chem. Commun. 2013, 49, 2329-2331. (b) Goel, R.; Luxami, V.; Paul, K. Synthesis of energy transfer cassettes via click and Suzuki-Miyaura cross-coupling reaction. RSC Adv. 2016, 6, 37664-37671. (c) Blaser, H.-U.; Indolese, A.; Naud, F.; Nettekoven, U.; Schnyder, A. Industrial R\&D on Catalytic $\mathrm{C}-\mathrm{C}$ and $\mathrm{C}-\mathrm{N}$ Coupling Reactions: A Personal Account on Goals, Approaches and Results. Adv. Synth. Catal. 2004, 346, 1583-1598. (d) Baudoin, O.; Cesario, M.; Guénard, D.; Guéritte, F. Application of the PalladiumCatalyzed Borylation/Suzuki Coupling (BSC) Reaction to the Synthesis of Biologically Active Biaryl Lactams. J. Org. Chem. 2002, 67, 1199-1207.

(14) (a) Miyaura, N.; Yamada, K.; Suzuki, A. A new stereospecific cross-coupling by the palladium-catalyzed reaction of 1-alkenylboranes with 1-alkenyl or 1-alkynyl halides. Tetrahedron Lett. 1979, 20, 3437-3440. (b) Tamao, K.; Sumitani, K.; Kumada, M. Selective carbon-carbon bond formation by cross-coupling of Grignard reagents with organic halides. Catalysis by nickel-phosphine complexes. J. Am. Chem. Soc. 1972, 94, 4374-4376. (c) Stille, J. K. Palladium catalyzed coupling of organotin reagents with organic electrophiles. Pure Appl. Chem. 1985, 57, 1771-1780. (d) Baba, S.; Negishi, E. A novel stereospecific alkenyl-alkenyl cross-coupling by a palladium or nickel catalyzed reaction of alkenylalanes with alkenyl halides. J. Am. Chem. Soc. 1976, 98, 6729-6731.

(15) (a) Chen, S.-N.; Wu, W.-Y.; Tsai, F.-Y. Hiyama reaction of aryl bromides with arylsiloxanes catalyzed by a reusable palladium(II)/ cationic bipyridyl system in water. Tetrahedron 2008, 64, 8164-8168. (b) Nuri, A.; Mansoori, Y.; Bezaatpour, A.; Shchukarev, A.; Mikkola, J. P. Magnetic Mesoporous SBA-15 Functionalized with a NHC Pd(II) Complex: An Efficient and Recoverable Nanocatalyst for Hiyama Reaction. ChemistrySelect 2019, 4, 1820-1829. (c) Hiyama, T. How I came across the silicon-based cross-coupling reaction. J. Organomet. Chem. 2002, 653, 58-61.

(16) (a) Hajipour, A. R.; Abolfathi, P. Nickel embedded on triazolemodified magnetic nanoparticles: A novel and sustainable heterogeneous catalyst for Hiyama reaction in fluoride-free condition. Catal. Commun. 2018, 103, 92-95. (b) Thapa, S.; Kafle, A.; Gurung, S. K.; Montoya, A.; Riedel, P.; Giri, R. Ligand-Free Copper-Catalyzed Negishi Coupling of Alkyl-, Aryl-, and Alkynylzinc Reagents with Heteroaryl Iodides. Angew. Chem., Int. Ed. 2015, 54, 8236-8240. (c) Zhu, Z.; Ma, J.; Xu, L.; Xu, L.; Li, H.; Li, H. Facile synthesis of Co-B amorphous alloy in uniform spherical nanoparticles with enhanced catalytic properties. ACS Catal. 2012, 2, 2119-2125. (d) Sindhu, K. S.; Thankachan, A. P.; Thomas, A. M.; Anilkumar, G. Iron-Catalyzed Sonogashira Type Cross-Coupling Reaction of Aryl Iodides with Terminal Alkynes in Water under Aerobic Conditions. ChemistrySelect 2016, 1, 556-559.

(17) (a) Gosmini, C.; Bégouin, J.-M.; Moncomble, A. Cobaltcatalyzed cross-coupling reactions. Chem. Commun. 2008, 28, 32213233. (b) Iyer, S.; Thakur, V. V. The novel use of $\mathrm{Ni}, \mathrm{Co}, \mathrm{Cu}$ and $\mathrm{Mn}$ heterogeneous catalysts for the Heck reaction. J. Mol. Catal. 2000, 157, 275-278. (c) Kumar, L. M.; Bhat, B. R. Cobalt pincer complex catalyzed Suzuki-Miyaura cross coupling-A green approach. Appl. Organomet. Chem. 2017, 827, 41-48. (d) Ansari, R. M.; Bhat, B. R. Schiff base transition metal complexes for Suzuki-Miyaura crosscoupling reaction. J. Chem. Sci. 2017, 129, 1483-1490.

(18) (a) Asghar, S.; Tailor, S. B.; Elorriaga, D.; Bedford, R. B. Cobalt-Catalyzed Suzuki Biaryl Coupling of Aryl Halides. Angew. 
Chem., Int. Ed. 2017, 56, 16367-16370. (b) Mohammadinezhad, A.; Akhlaghinia, $\mathrm{B} . \mathrm{Fe}_{3} \mathrm{O}_{4} @$ Boehmite- $\mathrm{NH}_{2}$-CoII NPs: an inexpensive and highly efficient heterogeneous magnetic nanocatalyst for the SuzukiMiyaura and Heck-Mizoroki cross-coupling reactions. Green Chem. 2017, 19, 5625-5641.

(19) (a) Nasir Baig, R. B.; Varma, R. S. Organic synthesis via magnetic attraction: benign and sustainable protocols using magnetic nanoferrites. Green Chem. 2013, 15, 398-417. (b) Hudson, R.; Feng, Y.; Varma, R. S.; Moores, A. Bare magnetic nanoparticles: sustainable synthesis and applications in catalytic organic transformations. Green Chem. 2014, 16, 4493-4505. (c) Reddy, L. H.; Arias, J. L.; Nicolas, J.; Couvreur, P. Magnetic nanoparticles: design and characterization, toxicity and biocompatibility, pharmaceutical and biomedical applications. Chem. Rev. 2012, 112, 5818-5878. (d) Laurent, S.; Forge, D.; Port, M.; Roch, A.; Robic, C.; Vander Elst, L.; Muller, R. N. Magnetic Iron Oxide Nanoparticles: Synthesis, Stabilization, Vectorization, Physicochemical Characterizations, and Biological Applications. Chem. Rev. 2008, 108, 2064-2110.

(20) Wang, L.; Park, H.-Y.; Lim, S. I.-I.; Schadt, M. J.; Mott, D.; Luo, J.; Wang, X.; Zhong, C.-J. Core@shell nanomaterials: Gold-coated magnetic oxide nanoparticles. J. Mater. Chem. 2008, 18, 2629-2635. (21) Stjerndahl, M.; Andersson, M.; Hall, H. E.; Pajerowski, D. M.; Meisel, M. W.; Duran, R. S. Superparamagnetic $\mathrm{Fe}_{3} \mathrm{O}_{4} / \mathrm{SiO}_{2}$ nanocomposites: Enabling the tuning of both the iron oxide load and the size of the nanoparticles. Langmuir 2008, 24, 3532-3536.

(22) Xu, L.; Zhang, W.; Ding, Y.; Peng, Y.; Zhang, S.; Yu, W.; Qian, Y. Formation, characterization and magnetic properties of $\mathrm{Fe}_{3} \mathrm{O}_{4}$ nanowires encapsulated in carbon microtubes. J. Phys. Chem. B 2004, 108, 10859-10862.

(23) Berry, C. C.; Wells, S.; Charles, S.; Curtis, A. S. G. Dextran and albumin derivatised iron oxide nanoparticles: influence on fibroblasts in vitro. Biomaterials 2003, 24, 4551-4557.

(24) (a) Guo, T.-Y.; Xia, Y.-Q.; Wang, J.; Song, M.-D.; Zhang, B.-H. Chitosan beads as molecularly imprinted polymer matrix for selective separation of proteins. Biomaterials 2005, 26, 5737-5745. (b) Baran, T.; Menteş, A. Microwave assisted synthesis of biaryls by C-C coupling reactions with a new chitosan supported Pd (II) catalyst. J. Mol. Struct. 2006, 1122, 111-116.

(25) (a) Liang, Y.-Y.; Zhang, L.-M. Bioconjugation of papain on superparamagnetic nanoparticles decorated with carboxymethylated chitosan. Biomacromolecules 2007, 8, 1480-1486. (b) Sinha, V. R.; Singla, A. K.; Wadhawan, S.; Kaushik, R.; Kumria, R.; Bansal, K.; Dhawan, S. Chitosan microspheres as a potential carrier for drugs. Int. J. Pharm. 2004, 274, 1-33.

(26) (a) Ayati, A.; Heravi, M. M.; Daraie, M.; Tanhaei, B.; Bamoharram, F. F.; Sillanpaa, M. $\mathrm{H}_{3} \mathrm{PMo}_{12} \mathrm{O}_{40}$ immobilized chitosan/ $\mathrm{Fe}_{3} \mathrm{O}_{4}$ as a novel efficient, green and recyclable nanocatalyst in the synthesis of pyrano-pyrazole derivatives. J. Iran. Chem. Soc. 2016, 13, 2301-2308. (b) Shaabani, A.; Borjian Boroujeni, M.; Laeini, M. S. Copper(II) supported on magnetic chitosan: a green nanocatalyst for the synthesis of 2,4,6-triaryl pyridines by $\mathrm{C}-\mathrm{N}$ bond cleavage of benzylamines. RSC Adv. 2016, 6, 27706-27713. (c) Naghipour, A.; Fakhri, A. Heterogeneous $\mathrm{Fe}_{3} \mathrm{O}_{4} @$ chitosan-Schiff base Pd nanocatalyst: Fabrication, characterization and application as highly efficient and magnetically-recoverable catalyst for Suzuki-Miyaura and Heck-Mizoroki C-C coupling reactions. Catal. Commun. 2016, 73, 39-45. (d) Hajipour, A. R.; Tavangar-Rizi, Z. Methioninefunctionalized chitosan-Pd(0) complex: A novel magnetically separable catalyst for Heck reaction of aryl iodide and aryl bromides at room temperature in water as only solvent. Appl. Organomet. Chem. 2017, 31, e3638-e3645. (e) Chetia, M.; Ali, A. A.; Bhuyan, D.; Saikia, L.; Sarma, D. Magnetically recoverable chitosan-stabilised copper-iron oxide nanocomposite material as an efficient heterogeneous catalyst for azide-alkyne cycloaddition reactions. New J. Chem. 2015, 39, 5902-5907.

(27) (a) Sobhani, S.; Vahidi, Z.; Zeraatkar, Z.; Khodadadi, S. A pd complex of a NNN pincer ligand supported on $\gamma-\mathrm{Fe}_{2} \mathrm{O}_{3} @ \mathrm{SiO}_{2}$ as the first magnetically recoverable heterogeneous catalyst for C-P bond forming reactions. RSC Adv. 2015, 5, 36552-36559. (b) Sobhani, S.;
Habibollahi, A.; Zeraatkar, Z. A novel water-dispersible/magnetically recyclable $\mathrm{Pd}$ catalyst for $\mathrm{C}-\mathrm{C}$ cross-coupling reactions in pure water. Org. Process Res. Dev. 2019, 23, 1321-1332. (c) Sobhani, S.; Chahkamali, F. O.; Sansano, J. M. A new bifunctional heterogeneous nanocatalyst for one-pot reduction-Schiff base condensation and reduction-carbonylation of nitroarenes. RSC Adv. 2019, 9, 13621372.

(28) Sobhani, S.; Hosseini Moghadam, H.; Skibsted, J.; Sansano, J. M. A hydrophilic heterogeneous cobalt catalyst for fluoride-free Hiyama, Suzuki, Heck and Hirao cross-coupling reactions in water. Green Chem. 2020, 22, 1353-1365.

(29) Huang, B.; Wang, Y.; Zhan, S.; Ye, J. One-step electrochemical deposition of Schiff base cobalt complex as effective water oxidation catalyst. Appl. Surf. Sci. 2017, 396, 121-128.

(30) Chen, P.; Yang, F.; Kostka, A.; Xia, W. Interaction of Cobalt Nanoparticles with Oxygen- and Nitrogen-Functionalized Carbon Nanotubes and Impact on Nitrobenzene Hydrogenation Catalysis. ACS Catal. 2014, 4, 1478-1486.

(31) Girardon, J.; Quinet, E.; Gribovalconstant, A.; Chernavskii, P.; Gengembre, L.; Khodakov, A. Cobalt dispersion, reducibility, and surface sites in promoted silica-supported Fischer-Tropsch catalysts. J. Catal. 2007, 248, 143-157.

(32) (a) Bayly, C. I.; Black, W. C.; Léger, S.; Ouimet, N.; Ouellet, M.; Percival, M. D. Structure-based design of COX-2 selectivity into flurbiprofen. Bioorg. Med. Chem. Lett. 1999, 9, 307-312. (b) Deep, A.; Jain, S.; Sharma, P. C.; Verma, P.; Kumar, M.; Dora, C. P. Design and biological evaluation of biphenyl-4-carboxylic acid hydrazide-hydrazone for antimicrobial activity. Acta Pol. Pharm. 2010, 67, 255-259. (c) Fleming, F. F.; Yao, L.; Ravikumar, P. C.; Funk, L.; Shook, B. C. Nitrile-containing pharmaceuticals: efficacious roles of the nitrile pharmacophore. J. Med. Chem. 2010, 53, 7902-7917.

(33) (a) Nehra, P.; Chauhan, R.; Garg, N.; Verma, K. Antibacterial and antifungal activity of chitosan coated iron oxide nanoparticles. $B r$. J. Biomed. Sci. 2017, 75, 13-18. (b) Safari, J.; Javadian, L. Ultrasound assisted the green synthesis of 2 -amino- $4 \mathrm{H}$-chromene derivatives catalyzed by $\mathrm{Fe}_{3} \mathrm{O}_{4}$-functionalized nanoparticles with chitosan as a novel and reusable magnetic catalyst. Ultrason. Sonochem. 2015, 22, $341-348$. 